\title{
BMJ Open Cultural adaptation of a patient decision-aid for insulin therapy
}

\author{
Ngiap Chuan Tan (D) , ,2 Agnes Koong Ying Leng, ${ }^{3}$ Ian Phoon Kwong Yun, ${ }^{3}$ \\ Sinead Wang Zhen, ${ }^{3}$ Muthulakshmi Paulpandi, ${ }^{1}$ Yew Kong Lee, ${ }^{4}$ John Furler (D) , \\ Josip Car (D), 6,7 Chirk Jenn $\mathrm{Ng}^{4}$
}

\begin{abstract}
To cite: Tan NC, Koong Ying Leng A, Phoon Kwong Yun I, et al. Cultural adaptation of a patient decision-aid for insulin therapy. BMJ Open 2020;10:e033791. doi:10.1136/ bmjopen-2019-033791

- Prepublication history and additional material for this paper are available online. To view these files, please visit the journal online (http://dx.doi. org/10.1136/bmjopen-2019033791).
\end{abstract}

Received 27 August 2019 Revised 15 November 2019 Accepted 13 February 2020

D) Check for updates

(c) Author(s) (or their employer(s)) 2020. Re-use permitted under CC BY-NC. No commercial re-use. See rights and permissions. Published by BMJ.

For numbered affiliations see end of article.

\section{Correspondence to}

Dr Ngiap Chuan Tan;

tan.ngiap.chuan@singhealth. com.sg

\section{ABSTRACT}

Introduction Patient decision-aids (PDAs) support patients in selecting evidence-based treatment options. PDA is useful only if the user understands the content to make personalised decisions. Cultural adaptation is a process of adjusting health messages so that the information is accurate, relevant and understandable to users from a different population. A PDA has been developed to assist Malaysian patients with secondary drug failure to initiate insulin therapy to control their type 2 diabetes mellitus (T2DM). Likewise, patients with T2DM in neighbouring Singapore face similar barriers in commencing insulin treatment, which a PDA may facilitate decision-making in selecting personalised therapy.

Objective The study aimed to explore the views and perceptions of Singaporean primary care providers on the Malaysia PDA to initiate insulin therapy and described the cultural adaptation process used in the design and development of a new PDA, which would be trialled in a Singapore primary healthcare institution.

Method Qualitative research method was deployed to conduct one-to-one in-depth interviews of the healthcare providers at the trial site (SingHealth Polyclinics-SHP), including six primary care physicians and four nurses to gather their views and feedbacks on the Malaysian PDA. The interviews were transcribed, audited and analysed (standard content analysis) to identify themes relating to the content, layout, concerns of the original PDA and suggestions to the design of the new SHP PDA. Results Cultural adaptation of the new PDA includes change to the overall design, graphics (including pictograms), presentation styles, additional contextualised content (personalisation, subheadings, cost and treatment option), modified phrasing of the subtitles and concerns (choice of words) relevant to the new users.

Conclusion A PDA on insulin therapy underwent cultural adaptation before its implementation in another population in a neighbouring country. Its relevance and effectiveness will be evaluated in future research.

\section{INTRODUCTION}

Patient decision-aid (PDA) is a tool to facilitate decision making by providing relevant information about their treatment options and probable outcomes to the target audience, and to allow clarification of their personal values and preferences. ${ }^{1}$ Such tools are often used in shared decision making

\section{Strengths and limitations of this study}

- The study shows that a patient decision-aid (PDA) can be culturally adapted for a different population via review and modification of its content, design, presentation and graphics.

- Qualitative feedbacks from targeted users (primary care providers), and input from the investigators are key steps to contextualise the PDA content in this cultural adaptation process.

- Cultural adaptation of a validated PDA is usually faster compared with one which has to be developed from scratch (cultural optimisation).

- Feedbacks from the patient-users will be gathered at the next 'lab testing phase' as a continuum of the cultural adaptation of the PDA.

- The cultural adaptation across different language used in the PDA could be different and await further research.

(SDM) between the healthcare provider and patient in situations when there are multiple options for investigation and treatment. ${ }^{23}$ The PDA needs to be contextualised to the local culture, the population's health literacy, the local clinic or hospital workflow, healthcare system and associated policies for it to enhance the SDM process.

PDAs have been developed to support SDM in the selection of therapeutic options to treat a wide range of conditions, from metabolic diseases to malignancy management. The development of these PDAs conventionally involves a series of steps and background studies: qualitative research to understand the values and preferences of the patients; identifying barriers faced by their care providers; assembling of the evidence-based treatment options; design and layout of the PDA; printing or digitalising the tool before pilot testing of the prototype. ${ }^{45}$ The entire process from conceptualising to prototyping can be long and costly but it is a necessary investment of resources in clinical area where essential information to make informed decision is lacking. ${ }^{6}$ 
Nonetheless, many PDAs have been developed over the past decade due to contributions from researchers worldwide, including those from the SDM pioneers in the Ottawa Hospital Research Institute. ${ }^{7}$ An inventory of these PDAs can be found at its website. ${ }^{8}$ It includes a PDA developed by a group of researchers from the University of Malaya (UM) on insulin initiation targeted at local Malaysians with poorly controlled type 2 diabetes mellitus (T2DM) despite being on multiple oral hypoglycaemic agents. This PDA was developed over the years using the conventional method and has been implemented in selected local public primary healthcare clinics (Poliklinik Kesihatan) in the Klang Valley in Malaysia. ${ }^{9} 10$

Singapore is an island state in close geographical proximity to peninsula Malaysia. Its population comprising multiethnic Asians (Chinese, Malays and Indians) is similar to those in Malaysia. Singaporeans, aged 18-69 years, also face increasing prevalence of T2DM from $4.3 \%$ in 1990 to an estimated $15.9 \%$ in $2050 .{ }^{11}$ In addition, the overall Singapore population is ageing rapidly due to declining birth rates and longer average lifespan of the individual. With the expectant increase in the number of years a patient has to live with diabetes, many will develop secondary drug failure over time and will require insulin to maintain normoglycaemia. ${ }^{12}$ Yet local studies have shown that patients with T2DM are reluctant to initiate insulin due to multiple factors. ${ }^{13} 14$ The barriers include misperception and poor understanding of the T2DM and its treatment by patients; failure to recognise the values and preferences by their healthcare providers; and/or lack of opportunities and practices in SDM by both stakeholders during their consultation in primary care setting. ${ }^{15}$ These barriers are identical to those faced by Malaysian patients with T2DM. ${ }^{16}$ There is a need to address these barriers towards insulin therapy to optimise glycaemic control in these patients.

Using a PDA to facilitate SDM between patients and their healthcare providers can potentially reduce the barrier towards insulin initiation. In view of the similarity between the populations in Singapore and Malaysia, we postulated that PDA developed by UM could be adapted and implemented in similar publicly funded primary care clinics (polyclinics) in Singapore. Nevertheless, literature suggests that culturally adapted health messages tend to be more effective when they are used in healthcare interventions. ${ }^{17} 18$ Bailey et al had also shown that a PDA, which they developed to intensify treatment of T2DM, resulted in significant improvement in the knowledge, decisional self-efficacy, and decisional conflict among the users in their pragmatic randomised controlled trial. ${ }^{19}$

Furthermore, the training and practices of primary healthcare providers, and the public primary healthcare infrastructure, financing policy and system delivery differ to various extents between the two nations. We postulated that differences in the views and expectations exist between the two groups of healthcare providers on the content and layout of the PDA, which could impact on their future PDA utility. Hence, this study aimed to explore the views and perceptions of Singapore primary care providers on the Malaysian PDA developed by UM and to report the cultural adaptation process used in the design and development of a new PDA to be used in a Singapore public primary healthcare institution.

\section{METHOD}

Qualitative research method was used to gather the views and perceptions of primary care providers at a polyclinic in the eastern region of Singapore.

\section{Study site}

This polyclinic is approximately $1760 \mathrm{~m}^{2}$ in size with open access to its 53800 multiethnic Asian residents. ${ }^{20}$ Its polyclinic 14 physicians and 28 nurses serve approximately 500 walk-ins and scheduled ambulatory patients daily during office hours. The polyclinic provides a wide range of primary healthcare services based on a subsidised copayment scheme by the patients. The T2DM Registry shows the primary care professionals manage 5471 patients with T2DM at this study site, of which $3.56 \%$ have HbA1c of $9.5 \%$ or higher based on its monthly quality indicators for T2DM. ${ }^{21}$ All the polyclinic healthcare team members manage patients with T2DM during their clinical work but SDM is not explicitly incorporated into the local clinical guidelines and practices. ${ }^{22}$

\section{Subjects}

AK is a member of the study team working at the study site. She provided her colleagues with the institution review board approved study information leaflets (which also contained the interview topic guide) and invited them to participate in the study voluntarily during the polyclinic staff meeting. A total of six polyclinic physicians and four nurse counsellors volunteered to be interviewed. They were then provided with a print copy of the original PDA (UM), which is available in four languages. All of them opted for the English version, as it is the common language of communication in Singapore. They were given at least 3 days to review the content and layout of the PDA (UM) before their scheduled interviews.

\section{Topic guide development}

The topic guide was aligned to the broader aims of the study to explore the views and perspectives of the participants (healthcare providers) on shared decision-making in initiating insulin as part of the intensification of the T2DM treatment of their patients and their comments on the use of the proposed PDA (online supplementary appendix 1). In the latter, the questions in the topic guide specifically seek their views on the depth and breadth of information and the language used in the UM PDA (figure 1).

\section{Interviews}

In-depth interviews were conducted on each de-identified participant using the topic guide after obtaining their written consent. Each interview was audio-recorded 
Content Review

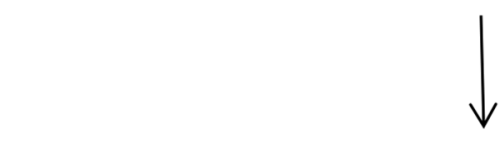

Inclusion of newer treatment options \& update / contextualize

content (e.g. cost of treatment)<smiles>C[AlH]</smiles>

Review of Layout Design

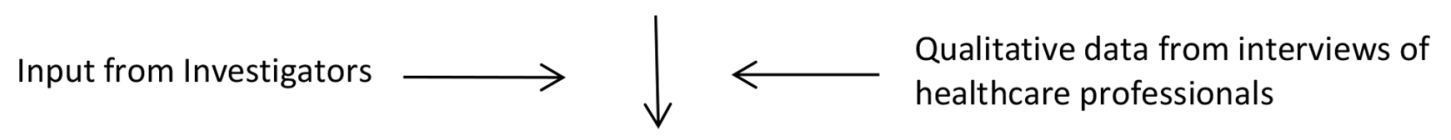

Modifications of Layout Design

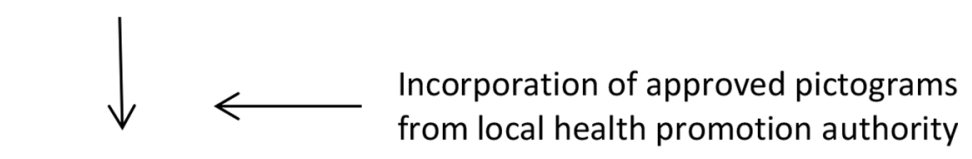

PDA Prototype

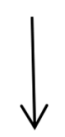

Field Testing of PDA on Patients

Figure 1 Cultural adaptation and development pathway of patient decision aid (PDA).

in a quiet room, which lasted $30-40 \mathrm{~min}$. To avoid conflict of interest, the interviewers from the study team were not staff at the study site. The recordings were transcribed into text and then coded by two independent study team members.

\section{Data analysis}

Using standard content analysis, the codes were used to identify emergent themes on the content, layout, applications and implementation of the PDA. Those pertaining to the content and layout were collated and identified as the potential areas of change in the design of the new PDA (SingHealth Polyclinics-SHP).

\section{Adaptation and transformation into the new PDA Content}

Investigators carried out content review to update the evidence on the effectiveness and adverse effects of the treatment options for T2DM, including new categories of oral (sodium glucose (SGLT2) inhibitors) and injectable (GLP-1 agonist) drug therapies, which are available in Singapore and would be included in the new PDA. These two treatment options were not available at the public Malaysian primary care clinics at the time of the review of the PDA (UM).

The investigators sought the assistance of the pharmacist to replace the estimated cost of the treatment options based on Singapore currency and local healthcare finance policies, which differ from those in Malaysia.

Layout

The format of the PDA prototype follows the guidelines from the Ottawa University Research Institute, which is open access via its website. ${ }^{7}$ The PDA includes the following segments: (1) knowledge; (2) values; (3) support and (4) certainty in making decision. Based on the qualitative data from the participants and iterative discussions among the investigators, features of the original PDA (UM) which were deemed relevant and essential were retained, modified or updated. The designer of both the PDA is the same person. ${ }^{23}$

The key processes in adapting the PDA for implementation at the new target population are depicted in a flow chart in figure 1 .

Patient and public involvement

No patient involved

\section{RESULTS}

The participants had comments pertaining to the dimensions of the UM PDA, its cover page, colour scheme, font size, graphics (including pictograms), presentation styles, flow of information, content (subheadings, 
personalisation, cost and treatment option) and concerns (choice of words) relevant to the local population.

The translation of the themes into changes in content and layout of the new PDA are summarised in table 1.

\section{DISCUSSION}

Cultural adaptation is defined as a process that looks at both language and cultural issues in the process of preparing a tool for use in another setting. ${ }^{24}$ The focus is finding cultural equivalents (such as words, examples and pictures) so that the information is accurate, relevant and understandable to the different cultural population. ${ }^{25}$

Cultural adaptation is prerequisite for the delivery of culturally competent interventions and positive health outcomes among multiethnic populations. ${ }^{26}$ In this study, cultural adaptation of a PDA developed in one academic institution was carried out before its introduction in another healthcare organisation in a second country. In spite of similar ethnic composition in the two populations, significant changes in content and layout were carried out to develop the new PDA (table 1). They include overall design, graphics (including pictograms), presentation styles, additional contextualised content (cost and treatment option), modified phrasing of subtitles and list of concerns relevant to the local population.

The cultural adaptation in this endeavour appears to match the key strategies developed by Kreuter $e t a l^{27}$ to promote cultural competency in healthcare programme development. ${ }^{27}$ The culturally adapted SHP PDA will be a key tool to engage patients with poorly controlled T2DM in a subsequent trial. Kreuter et al described five "categories of strategies' ${ }^{27}$ As illustrated in table 1, vibrant colour scheme and image of insulin injectable pens are introduced in the SHP PDA to enhance receptivity and acceptance of the material under the 'Peripheral category of strategy'. Facts and evidences are updated on the health topic in the 'Evidential category'. While English is used in both PDA, the choice of words differs slightly in certain segments (refer to results) so as to increase accessibility and understanding of the content under the 'Linguistic' category.

Removal of the concern that insulin is non-halal in the SHP PDA is an example of change under the 'Sociocultural' category. In Malaysia, the majority ethnic group comprises Muslim Malays, who are concerned about the source of the insulin and is explicitly highlighted as a potential concern in the UM PDA. It was not in the SHP PDA as local primary care providers are aware that insulin and its analogues available in Singapore are halalcertified, besides, it is not a major or common concern among local Muslim patients. Provision of an open-ended 'other' option also allows patients to raise this concern.

The aim of 'Constituent-involving' is to enhance the understanding and 'buy-in' of the tool. Hence, the native primary healthcare providers in the institution were involved in the interviews to gather their feedback on the content and layout, focusing on the content and layout. The objective is to understand their views of the PDA and to determine if the proposed tool addresses the main issues encountered during their prior interaction with the target patients. We postulate that the implementation of this PDA is more likely to be successful when the providers understand the objectives of SDM and PDA and are involved in the content revision as well as the design of the PDA. During the interview, their willingness to use the PDA was assessed. All the interviewees expressed that they were keen to try it. The investigators will continue to gather their input after the PDA prototype is introduced to patients in the subsequent feasibility study.

The patients or lay persons are the other main group of users. Their views and input will be sought after the PDA prototype is introduced to them in actual clinical setting in the next phase of the study. What is more critical to the latter is their understanding of the PDA content when the provider communicates the content to them according to the layout of the tool. The investigators will leverage on the feedback from both the providers and the patients to refine the PDA before the finalised version is scaled up for routine clinical use in the institution. ${ }^{28}$

The proposed implementation of this PDA is aligned to the four phases recommended by Chenel $e t$ al in their scoping review on the cultural adaptation and validation of PDAs. ${ }^{29}$ What had been accomplished constitutes the exploration and adaptation phases, the providers and the patients will next be involved in the usability testing, exploration of PDA acceptability, test-retest reliability, content, construct and criterion validation in the subsequent lab and field testing phases. ${ }^{29}$

The cultural adaptation process of the SHP PDA is summarised in a flow chart (figure 1). The process took 8 months to complete, from the commencement of the qualitative research involving interviews of the primary care providers to its registration for the International Standard Book Number. As alluded by Chenel $e t a l,{ }^{29}$ the next step is to conduct usability, acceptability and reliability testing, and validation studies of the PDA by the patients and their providers. Success will be rated from its eventual implementation in routine clinical practice, which will require further evaluation of its reach, effectiveness, adoption and scalability using implementation science. Modifications of the PDA will be carried out iteratively to update its content and to cater to the changing demography of the population, including their literacy levels.

Another process to accelerate the PDA development is to translate the tool to local languages before its clinical application. Whether this simplified method to produce a translated PDA attains the same objective compared with one which undergoes cultural adaptation remains to be proven by robust scientific evidence.

The cultural adaptation of the SHP PDA was based on the English version of the UM PDA. The process of cultural adaptation of PDA across different language is unclear and awaits further research to gain insight. Professional certified linguists have performed forward 
Table 1 Cultural adaptions of the UM PDA to develop the SHP PDA

\begin{tabular}{|c|c|c|c|}
\hline Features (codes) & $\begin{array}{l}\text { Qualitative feedbacks from primary } \\
\text { healthcare providers (verbatim) }\end{array}$ & PDA (UM) & PDA (SHP) \\
\hline \multicolumn{4}{|l|}{ Design and presentation } \\
\hline Dimensions and pages & $\begin{array}{l}\text { 'If the PDA has more pages, } \\
\text { information about 'insulin therapy' ... } \\
\text { (we) can explain each symptom ... }\end{array}$ & $\begin{array}{l}20.2 \times 20.2 \mathrm{~cm} \text { booklet, comprising } 16 \\
\text { pages }\end{array}$ & $\begin{array}{l}17.3 \times 25.0 \mathrm{~cm} \text { booklet, comprising } 20 \\
\text { pages }\end{array}$ \\
\hline
\end{tabular}

what happens when your blood sugar

is high?' Doctor

\begin{tabular}{|c|c|c|c|}
\hline Colour scheme & $\begin{array}{l}\text { Investigators propose warm colour } \\
\text { scheme and align to corporate } \\
\text { branding }\end{array}$ & Blue and green background & Predominantly orange background \\
\hline Key feature on cover page & $\begin{array}{l}\text { 'The PDA doesn't really show the } \\
\text { pictures of the needle itself.' Doctor }\end{array}$ & Insulin Pen without revealing the needle & $\begin{array}{l}\text { A pair of hands showing insulin pen with } \\
\text { needle }\end{array}$ \\
\hline Font type & $\begin{array}{l}\text { The font type was recommended by } \\
\text { designer }\end{array}$ & Helvetica Neue (regular) & Futura Std (medium) \\
\hline Text font size & $\begin{array}{l}\text { 'The font size could be bigger' Doctor } \\
\text { 'For old people, they might prefer a bit } \\
\text { bigger font.' Nurse }\end{array}$ & Font size (height): $10 \mathrm{pt}$ & Font size (height): $12 \mathrm{pt}$ \\
\hline Illustrations & $\begin{array}{l}\text { 'Pictures of various complications can } \\
\text { be added ... will be (of) concern of } \\
\text { patients' Doctor } \\
\text { 'some pictures showing how pancreas } \\
\text { releases sugar ... pictures will be } \\
\text { catchy for the patients and they will } \\
\text { understand better' Nurse }\end{array}$ & Entirely text-based content & $\begin{array}{l}\text { Pictograms inserted in segments on: } \\
\text { 'what happens when your blood sugar is } \\
\text { high?' and 'Type } 2 \text { Diabetes and Insulin' }\end{array}$ \\
\hline Summary Page of Treatment Options & $\begin{array}{l}\text { 'the flow (diagram) will be more clear' } \\
\text { Doctor }\end{array}$ & $\begin{array}{l}\text { Presentation in the form of six branches: } \\
\text { each branch represents one treatment } \\
\text { option }\end{array}$ & $\begin{array}{l}\text { Presentation in the form of seven } \\
\text { cogwheels: each cogwheel represents } \\
\text { one treatment option. }\end{array}$ \\
\hline $\begin{array}{l}\text { Design on page on 'support' and } \\
\text { 'decision' }\end{array}$ & $\begin{array}{l}\text { 'As in the sort of diagrams like tables } \\
\text {.... if possible to put flow chart' Doctor }\end{array}$ & $\begin{array}{l}\text { Design in the format of leafs with 'yes' } \\
\text { and 'no' responses as extension of } \\
\text { each leaf, which are consistent with the } \\
\text { general design of the entire PDA. }\end{array}$ & $\begin{array}{l}\text { Design for 'support' in the form of } \\
\text { machinery and 'decision' in two columns }\end{array}$ \\
\hline Personal notes & $\begin{array}{l}\text { '(make it) personalized - there is an } \\
\text { option to write your name, put your } \\
\text { IC number, put your primary care } \\
\text { provider' Doctor } \\
\text { 'there should be column for them to } \\
\text { write their views' Doctor }\end{array}$ & $\begin{array}{l}\text { Provision for entry of personal notes at } \\
\text { the rear of the PDA }\end{array}$ & $\begin{array}{l}\text { Provision for entry of personal notes at } \\
\text { the rear of the PDA }\end{array}$ \\
\hline \multicolumn{4}{|l|}{ Content } \\
\hline Languages & $\begin{array}{l}\text { 'With regards to the language used, } \\
\text { we need to customize to our multi } \\
\text { ethnic group needs.' Nurse }\end{array}$ & Available in four languages & Available in three languages \\
\hline $\begin{array}{l}\text { Listing and number of treatment } \\
\text { options }\end{array}$ & 'SGLT2 inhibitors are missing.' Doctor & $\begin{array}{l}\text { Six treatment options: no specification of } \\
\text { types of oral or parenteral medications }\end{array}$ & $\begin{array}{l}\text { Seven treatment options. For oral } \\
\text { and parenteral medications, specific } \\
\text { categories of medication are presented, } \\
\text { together with common examples. For } \\
\text { example SGLT-2 inhibitors (Example: } \\
\text { DapaglfloZin) }\end{array}$ \\
\hline Cost of treatment options & $\begin{array}{l}\text { 'We can state the cost range for } \\
\text { the insulin usage. It is quite difficult } \\
\text { because the cost fluctuates; the insulin } \\
\text { cost and the glucose monitoring } \\
\text { glucometer and the strip will fluctuate. } \\
\text { You can state as estimated cost. } \\
\text { Of course, it is in Ringgit. When } \\
\text { reproduce make it into Sing Dollars.' } \\
\text { Doctor }\end{array}$ & $\begin{array}{l}\text { Range of costing in Malaysian currency } \\
\text { (Ringgit) per unit (pen) or duration (per } \\
\text { day or per month) }\end{array}$ & $\begin{array}{l}\text { Range of costing in Singapore currency } \\
\text { (Singapore dollars), which includes } \\
\text { consumables such as needles per } 4 \\
\text { weeks based on specific quantum of } \\
\text { medication used ( } 10 \text { units of insulin per } \\
\text { day). Context: the patient is charged } \\
\text { each medication per week. }\end{array}$ \\
\hline Glycaemic control targets & $\begin{array}{l}\text { 'in the local context, people may } \\
\text { be followed up somewhere else } \\
\text { (hospitals) than polyclinic setting ... (to } \\
\text { indicate) blood sugar control (page 2) } \\
\text { expressed in both millimoles per litre } \\
\text { and milligram per litre.' Doctor }\end{array}$ & $\begin{array}{l}\text { Target in ranges for fasting }(4.4- \\
6.1 \mathrm{mmol} / \mathrm{L}) \text {; non-fasting blood sugar } \\
(4.4-8.0 \mathrm{mmol} / \mathrm{L}) \text { and single } \mathrm{HbA} 1 \mathrm{c} \text { target } \\
(<6.5 \%)\end{array}$ & $\begin{array}{l}\text { Pre-meal glucose range }(4-7 \mathrm{mmol} / \mathrm{L} \text { or } \\
72-126 \mathrm{mg} / \mathrm{dL}) \text {; } \\
2 \text {-hour post meal glucose range } \\
\text { ( }<10 \mathrm{mmol} / \mathrm{L} \text { or }<180 \mathrm{mg} / \mathrm{dL}) ; \\
\mathrm{HbA} 1 \mathrm{c} \text { target options }(6.5 \% \text { or } \\
\leq 7 \% \text { or }<8 \%)\end{array}$ \\
\hline
\end{tabular}

Continued 
Table 1 Continued

\begin{tabular}{ll}
\hline Features (codes) & $\begin{array}{l}\text { Qualitative feedbacks from primary } \\
\text { healthcare providers (verbatim) }\end{array}$ \\
\hline Highlighting risk of treatment & 'not all the common concerns were \\
& addressed in the booklet' Doctor \\
'Complications like physical & impairment (blindness) ... patients \\
& cannot see properly to inject. Some \\
people may have tremor, so they & cannot hold the needle properly.' \\
& Doctor \\
'more can be added about the small \\
side effects of the insulin therapy like \\
atrophy, that kind of skin changes.' \\
Doctor
\end{tabular}

PDA (UM)

Entitled 'Does insulin have side effects?' on half a page, focusing on recognising and managing hypoglycaemia and weight gain

PDA (SHP)

Grouped under 'What are your concerns?' over two pages. Enlist treatment-related concerns on pain from injection; side-effects on kidney (perceived damage); weight gain; hypoglycaemia; lipodystrophy; inconvenience; expenses; discontinuity of insulin; whether insulin is halal; continuity of oral medications; addiction to insulin; necessity of use of insulin; disease progression after insulin initiation; social embarrassment; family support and open option to discuss othe concerns, if any.

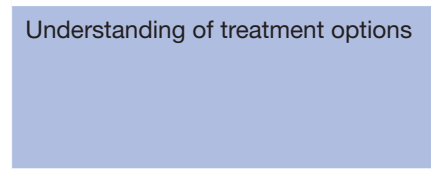

Understanding personal values and preferences in relation to treatment selection
'Generally it is sufficient to provide the required information for the patient who we have given the option for the first time to choose their treatment.' Nurse

'Page 10 (What is important to you?): I think it is quite useful. It's a kind of assurance. Patients can go through this booklet and make an effort to answer the questions. So they get to see what this option does and another option does. It clears their mind ... to make a decision.' Doctor

Understanding concerns
'...more on the insulin side-effects;
Actually there may be more than few;
the patient may be concerned about
'Insulin may damage my kidney',
which is not the case; that concern
(has to be) addressed.' Doctor

PDA, patient decision-aid; SHP, SingHealth Polyclinics; UM, University of Malaya.
Entitled 'Do you know enough about the treatment options?'

Assessment using four questions. No answer is provided.

Page is entitled 'What is important to you?'

Presented as three overlapping circles and text in two circles subtitled 'Starting Insulin' and 'Not Starting Insulin'

followed by 'I want to...' and 'I want to avoid...'

\section{Listing of known or common concerns} in phrases, including 'whether insulin is halal'

\section{Entitled 'Quiz Time!' Assessment using} four questions. Answers are provided.

Page is entitled 'What is important to you?'

Presented in two columns entitled 'I want to...' and 'I want to avoid...' and backward translation of the English version of the SHP PDA to produce the Mandarin and Malay versions to cater to the non-English speaking Chinese and Malay patients respectively. The effectiveness of these translated PDA, compared with the culturally adapted English version, will be evaluated in a separate study.

\section{CONCLUSION}

An English-based PDA on insulin therapy underwent cultural adaptation before its planned implementation in a separate nation was carried out. Gathering qualitative feedbacks from primary care providers, coupled with iterations from the investigators in the review of content and layout of the PDA, are key steps in this cultural adaptation process. The culturally adapted PDA will be implemented to support decision-making in selecting treatment options among patients with poorly controlled T2DM in the next phase of the study.

\section{Author affiliations}

${ }^{1}$ Department of Research, SingHealth Polyclinics, Singapore, Singapore

${ }^{2}$ Duke-NUS, Singapore, Singapore

${ }^{3}$ General Practice, SingHealth Polyclinics, Singapore, Singapore

${ }^{4}$ Department of Primary Care Medicine, University of Malaya, Kuala Lumpur, Malaysia
${ }^{5}$ Department of General Practice and Primary Health Care, University of Melbourne, Carlton, Victoria, Australia

${ }^{6}$ Health Services and Outcomes Research Programme, Lee Kong Chian School of Medicine, Nanyang Technological University, Singapore, Singapore

${ }^{7}$ Global eHealth Unit, Department of Primary Care and Public Health, School of Public Health, Imperial College London, London, UK

Contributors NCT and CJN developed the substudy concept. NCT, CJN, MP and YKL conducted the interviews. MP transcribed the audio recordings. NCT and MP coded the data. NCT and YLAK analysed the qualitative data. NCT, YLAK, YKL, JF, JC, KYIP and ZSW interpreted the results. NCT, MP, KYIP and ZSW drafted the manuscript and all authors revised the manuscript and approved the final version to be published.

Funding The study is sponsored by Singapore National Medical Research Council Health Services Research Grant (NMRC/HSRG/0082/2017).

Competing interests None declared.

Patient consent for publication Not required.

Ethics approval All procedures, including the informed consent process, were conducted in accordance with the ethical standards of Human Biomedical Research Act 2015. All participants provided signed informed consent. Ethics approval was granted by the SingHealth Central Institutional Review Board (2017/2823).

Provenance and peer review Not commissioned; externally peer reviewed.

Data availability statement The data and other related material are available upon request to the corresponding author.

Open access This is an open access article distributed in accordance with the Creative Commons Attribution Non Commercial (CC BY-NC 4.0) license, which permits others to distribute, remix, adapt, build upon this work non-commercially, and license their derivative works on different terms, provided the original work is 
properly cited, appropriate credit is given, any changes made indicated, and the use is non-commercial. See: http://creativecommons.org/licenses/by-nc/4.0/.

\section{ORCID iDs}

Ngiap Chuan Tan http://orcid.org/0000-0002-5946-1149

John Furler http://orcid.org/0000-0003-0339-5848

Josip Car http://orcid.org/0000-0001-8969-371X

\section{REFERENCES}

1 Feldman-Stewart D, O’Brien MA, Clayman ML, et al. Providing information about options in patient decision AIDS. BMC Med Inform Decis Mak 2013;13:1-9.

2 Bae J-M. Shared decision making: relevant concepts and facilitating strategies. Epidemiol Health 2017;39:e2017048.

3 Bae J-M. Development and application of patient decision AIDS. Epidemiol Health 2015;37:e2015018.

4 Légaré F, Witteman HO. Shared decision making: examining key elements and barriers to adoption into routine clinical practice. Health Aff 2013;32:276-84.

5 Lee YK, Low WY, Ng CJ. Exploring patient values in medical decision making: a qualitative study. PLoS One 2013;8:e80051.

6 Sepucha KR, Abhyankar P, Hoffman AS, et al. Standards for universal reporting of patient decision aid evaluation studies: the development of SUNDAE checklist. BMJ Qual Saf 2018;27:380-8.

7 O'Connor A, Stacey D, Jacobsen MJ. Patient Decision Aids - Ottawa Hospital Research Institute, 2017. Available: https://decisionaid.ohri. ca/ODST/index.php [Accessed 10 Jan 2019].

8 Patient Decision Aids Research Group. Decision aid library inventory (DALI. Ottawa: Ottawa Hospital Research Institute, 2013. http:// decisionaid.ohri.ca/cochinvent.php

9 Syed A, Mohd Don Z, Ng CJ, et al. Using a patient decision aid for insulin initiation in patients with type 2 diabetes: a qualitative analysis of doctor-patient conversations in primary care consultations in Malaysia. BMJ Open 2017;7:e014260.

10 Lee YK, Ng CJ, Lee PY, et al. What are the barriers faced by patients using insulin? A qualitative study of Malaysian health care professionals' views. Patient Prefer Adherence 2013;7:103-9.

11 Phan TP, Alkema L, Tai ES, et al. Forecasting the burden of type 2 diabetes in Singapore using a demographic epidemiological model of Singapore. BMJ Open Diabetes Res Care 2014;2:e000012.

12 Pitocco D, Valle D, Rossi A, et al. Unmet needs among patients with type 2 diabetes and secondary failure to oral anti-diabetic agents. $J$ Endocrinol Invest 2008;31:371-9.

13 Tan NC, Tan AM, Yeo JP, et al. Rethink: an observational cross sectional study on the uptake of insulin therapy among type 2 diabetes patients with secondary drug failure treated in primary care. Asia Pac Fam Med 2003;2:157-65.

14 Tan AM, Muthusamy L, Ng CC, et al. Initiation of insulin for type 2 diabetes mellitus patients: what are the issues? A qualitative study. Singapore Med J 2011;52:801-9.
15 Menear M, Garvelink MM, Adekpedjou R, et al. Factors associated with shared decision making among primary care physicians: findings from a multicentre cross-sectional study. Health Expect 2018;21:212-21.

16 Tong WT, Lee YK, Ng CJ, et al. Factors influencing implementation of a patient decision aid in a developing country: an exploratory study. Implement Sci 2017;12:40.

17 Légaré F, Adekpedjou R, Stacey D, et al. Interventions for increasing the use of shared decision making by healthcare professionals. Cochrane Database Syst Rev 2018;7:CD006732.

$18 \mathrm{Ng}$ CJ, Lee YK, Lee PY, et al. Health innovations in patient decision support: bridging the gaps and challenges. Australas Med $J$ 2013;6:95-9.

19 Bailey RA, Pfeifer M, Shillington AC, et al. Effect of a patient decision aid (PDA) for type 2 diabetes on knowledge, decisional self-efficacy, and decisional conflict. BMC Health Serv Res 2016;16:10.

20 SingHealth. Polyclinics- marine parade. Available: https://polyclinic. singhealth.com.sg/patient-care/shp-marineparade [Accessed $10 \mathrm{Nov}$ 2017].

21 Ministry of Health, Singapore. Top 4 conditions of Polyclinic attendances, Singapore health facts, statistics, Ministry of health, Singapore, 2015. Available: https://www.moh.gov.sg/content/moh_ web/home/statistics/Health_Facts_Singapore/ [Accessed 6 Jun 2015].

22 Ministry of Health, Singapore. Clinical practice guidelines, Ministry of health, Singapore, 2017. Available: https://www.moh.gov.sg/hpp/ doctors/guidelines/GuidelineDetails/cpgmed_diabetes_mellitus [Accessed 10 Nov 2017].

23 aid Idecision, team DP, Malaya Uof. The insulin patient decision aid. Available: https://dmit.um.edu.my/book [Accessed 10 Nov 2017].

24 Beaton DE, Bombardier C, Guillemin F, et al. Guidelines for the process of cross-cultural adaptation of self-report measures. Spine 2000;25:3186-91.

25 Centre for Addition and Mental Health (CAMH). Cultural counts: a roadmap to health promotion. Toronto, Canada. September, 2007. Available: https://holadoctor.net/pdf/HolaDoctor_Cultural_ Adaptation_for_Health_Protocol.pdf [Accessed 10 Jan 2019].

26 Attridge M, Creamer J, Ramsden M, et al. Culturally appropriate health education for people in ethnic minority groups with type 2 diabetes mellitus. Cochrane Database Syst Rev 2014:Art. No.: CD006424.

27 Kreuter MW, Lukwago SN, Bucholtz RDDC, et al. Achieving cultural appropriateness in health promotion programs: targeted and tailored approaches. Health Educ Behav 2003;30:133-46.

28 Healthwise. Shared decision making - Diabetes Type 2: Should I Take Insulin?Available: http://whatworksforhealth.wisc.edu/ program. php?t1=22\&t2=17\&t3=28\&id=589 [Accessed 10 Jan 2019].

29 Chenel V, Mortenson WB, Guay M, et al. Cultural adaptation and validation of patient decision AIDS: a scoping review. Patient Prefer Adherence 2018;12:321-32 https://doi.org/ 